cavity and the edges of the opening were green and sloughy. There was much swelling of the upper aperture of the larynx. The right upper and the left lower lobes of the lungs were affected throughout with broncho-pneumonia which had in many places broken down, giving rise to multiple abscesses. The other organs were healthy.

Bibliography.-Abel: Bactériologie de la Stomatite et de l'Angine Ulcéreuse, Centralblatt für Bakteriologie und Parasitologie, July 15th, 1898. C. Baron : Archiv fïr Kinderheilkunde, 1903, p. 161. Bernheim Ueber ein Bakterium befund bei Stomatitis Ulcerosa, Centralblatt für Bakteriologie und Parasitologie, Feb. 11th, 1898. De Stecklin : Contribution à l'Étiologie des Angines Ulcéro-membraneuses, Centralblatt fïr Bakteriologie und Parasitologie, November, 1898 Hess : Deutsche Medicinische Wochenschrift, Oct. 18th, 1903. Lacquépée : Sur cinq cas d'Angine à Spirilles et Bacilles Fusiformes de Vincent, Bulletins de la Société Médicale des Hôpitaux, Jan. 19th, 1899. Lemoine : Angine Ulcéro-membraneuse à Bacilles Fusiformes et Spirilles, Bulletins de la Société Médicale des Hôpitaux, March 18th 1898. Niclot et Marotte : Revue de Médecine, 1901, p. 317. Raoul and Thiry : Des Amygdalites Ulcéro-membraneuses avec Spirilles et Bacilles Fusiformes de Vincent, Congrès d'Otologie, de Laryngologie, et de

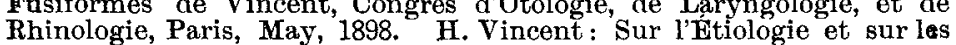
Lésions Anatomo-pathologiques de la Pourriture d'Hôpital, Annales de Lésions Anatomo-pathologiques de la Pourriture d'Hôpital, Annales de Institut Pasteur, Sept. 25th, 1896; Sur une Formo Particulière d'Angine Diphthéroide, Bulletins de la Société Médicale des Hôpitaux, March 11th, 1898 ; Nouvelles Recherches sur l'Angine Diphthéroide à Bacilles FusiAormes, ibid., Jan. 12th, 1899 ; Recherches Bactériologiques sur l'Angine
à Bacilles Fusiformes, Annales de l'Institut Pasteur, August 25th, 1899 .

\section{DIET IN CHRONIC HEART DISEASE.}

\section{By Professor THEOdOR SCHO'TT, M.D.}

As a kind of supplement to a discussion which took place at a meeting of the British Balneological and Climatological Society in the spring of last year and, moreover, in accordance with the express wish of numerous practitioners, I will now endeavour briefly to pass in review some general rules with respect to the diet which $I$ have found satisfactory in the treatment of chronic heart disease during the year. Only such points will be discussed at length as have a direct relation to heart diseases.

The principal rules, which are, in fact, to be regarded as fundamental, may be conveniently summed up in the two following clauses : (1) patients must aroid everything which excites the action of the heart; and (2) everything must be avoided which embarrasses the action of the heart.

The substances which most readily cause excited action of the heart are in the first place strong coffee or strong tea and in the next place strong alcoholic liquors. It is to be observed that in persons who from youth upwards have made free use of coffee or tea, either in great quantities or in strong infusion, if they come to suffer from heart disease a relatively small quantity of such habitual stimulants will be found to aggravate the cardiac symptoms. This is the reason why in Germany the medical men are just as strongly opposed to coffee drinking by sufferers from heart disease as in England they are opposed to tea-drinking in like circumstances. With regard to alcohol, its use as a daily beverage in an undiluted form, whether whisky or brandy, must be avoided as much as possible, and it must in any case be given only to patients for whom it is either indispensable as a stimulant or who have taken it for so many years that the sudden withdrawal of it might be dangerous in view of the possibility of collapse. In such cases the best plan is to give Rhine wine, Moselle, or Bordeaux which has been matured (gelagert) for eight or ten years, because in newer wines there is not only a larger proportion of fusel oil but experience also shows that there still exist too many fermentable substances which may very easily act injuriously. A tablespoonful of old Cognac brandy or whisky for some patients and an ounce of old sherry or port for others are almost indispensable as stimulants in cardiac weakness, but, as has been already said, if taken regularly they are capable of doing harm by producing cardiac irritability. It must here be remarked that a light or diluted wine agrees best with patients in Southern or Central Europe, whereas in Northern Europe, and especially in damp northern climates, a typical example of which is to be found in Great Britain, preference should, on the contrary, be given to Cognac brandy or whisky mixed with plain water and diluted until the proportion of the alcohol component is reduced nearly to that of moderately strong or even light wines. It is very necessary to forbid the addition of aromatic substances (such as ginger) to the alcohol, for simultaneous irritability of the stomach and heart often lead to loss of appetite and insomnia.

Moderate quantities of ordinary water or milk are by farthe best beverages ; next in order come tea or coffee, both of: them with copious addition of milk. Patients for whom. some fatty material is desirable may take cream either by itself or mixed with milk. Sterilised cream agrees better with many patients and it has the further advantage that it is not apt to produce flatulence. Cocoe deprived of its fat can be strongly recommended, whereas chocolate is seldom. found to agree well, either on account of the quantity of: sugar which it contains or from the stow digestibility of: cocoa fat, and the vanilla present in it often has the effect. of exciting the heart. The amount of fluid which may be: taken at one and the same time will be referred to presently

With respect to the second rule above given, it is of the: first importance that the patient should aroid taking enough. to cause any considerable distension of the stomach and that he should eat nothing which is difficult of digestion or tends to produce flatulence. It hardly requires to be explained in. detail how indigestible substances remain too long in the: stomach and prove injurious in consequence of the intimate: connexion between the nerves of the heart and stomach. Too hearty eating or the ingestion of substances which produce flatulence may be harmful in three ways. 1. Thediaphragm is pressed up against the lungs so that respination is impeded and the shortness of breath and dyspncea thence arising are well known to be peculiarly injurious to sufferersfrom heart disease. 2. The distended stomach also presses the diaphragm directly against the heart, forces the heart upwards and outwards, and displaces it in the direction of its base in such a way that its action can only be carried om with a greatly increased effort. 3. In like manner the intraabdominal pressure is augmented and the abdominal vessels are compressed. The general result is that the heart is weakened and the cardiac muscle not unfrequently suffers in the struggle. For this reason effervescing beverages, whether carbonated water, champagne, or beer, for the most part disagree with patients who are the subjects of heart disease. In the case of beer, which is essentially the product of an. artificially interrupted carbonic acid fermentation, the irritant properties of the extractives which it contains have also to be considered. Palpitation, shortmess of breath, and conditions favourable to arterio-sclerosis are only too often met with as after-effects of effervescing alcoholio drinks.

As such patients must never eat until a feeling of repletion is induced the generally accepted system of having three meals a day is not advisable for them and it is much better to take small amounts of food at whorter intervals. If the patients are very weak or very ill it may be necessary for them to have food every two hours, but in general food every three hours is often enough, the last meal of the day being taken two and a half or three hours before bedtime, for if this is neglected the result will be a bad night or at least broken sleep, which is apt to be followed by general irritability and cardiac difficulties of many kinds. If in any way possible, each of the daily meals ought to have about the same nutritional value, because this, apart from its utility for digestion, conduces best to a uniformly beneficial effect on the heart. With regard to individual dishes it must in the first place be specially pointed out that it is not advisable to take: considerable quantities of soup, because from the meat extractives which they contain soups in general, and either clear soups made from fresh meat or consommés in particular, are apt to produce a disturbing effect out of proportion: to their nutritional capacity. Even soups of which any kind of solid addition (Einlage) forms a part have but little food" value in proportion to their bulk, so that no more than a moderate quantity (only a few tablespoonfuls) can be recommended, for larger amounts interfere with the taking of really useful substances. New bread, whether brown or white, and freshly baked cakes are totally to be avoided, for they too often cause distension of the stomach and great flatulence. Toast, zwieback (a kind of rusk or "pulled" bread") made without sugar, or the crust of rolls may, however, be taken. Among vegetables those are to be. , avoided which are either difficult of digestion or productive of flatulence, such as beans, peas, lentils, sauerkraut (preserved eabbage), red cabbage, leeks, onions, garlic, and celery. Potatoes in the form of purée or simply boiled in water are to be preferred to the less digestible baked potatoes. Turnips and carrots should be eaten only when fresh and young. In other respects, fresh and easily digestible vegetables cannot be too highly commended. 
Animal food in its various forms, especially fish and pouitry, are allowable, but it hardly needs to be said that certain indigestible articles included under the heading of fish and poultry are to be forbidden ; eels, fat goose breasts, and goose-liver pies are examples of this kind. The same rule applies to rich sauces or mayonnaise, for salmon, lobsters, and crabs taken with these accompaniments are much more trying to cardiac patients than they otherwise would be. Oysters, mussels, and game (Wildbret) seldom do harm if fresh and prepared in a plain style, but highly smoked and salted fish or meat are objectionable because the great thirst which they produce easily tends to too much water being drunk. Among fatty substances butter and cream are by far the best, being easy of digestion. Fat bacon or the fat on a ham is, on the contrary, to be avoided on account of its indigestibility. The same rule applies to the hearty eating of fat. Oil generally does not agree well. Hot seasonings are injurious, red and black pepper being worst of all. They not only produce gastric irritation and great thirst but they have a specially harmful influence on the kidneys, an influence which in cases of weak heart may lead to conditions full of danger. Sausages, goulasch (a kind of meat stew), and salads containing pepper are therefore to be avoided. On the other hand, vegetable salads without hot seasoning, and particularly when made with lemon-juice, are permissible. There are many other seasonings or spices, such as nutmeg, mace, cinnamon, and vanilla, which are capable of doing harm by their tendency to quicken the action of the heart. The same thing may be said of horse-radish, which not only is apt to produce flatulence but also irritates the mucous membrane.

Easily digestible fruit stewed with the addition of a little sugar can be recommended, particularly on account of its favourable influence on gastro-intestinal peristalsis which is often so much impaired in heart disease that obstinate constipation is the result. For the same reason raw fruits which have to be peeled, such as apples, pears, apricots, peaches, and oranges, are often desirable. Grape-stones may act as irritants and should be removed before the fruit is eaten. On the other hand, raspberries, gooseberries, currants, bilberries, cranberries, pineapples, walnuts, Brazil nuts, and hazel nuts are to be prohibited, even when deprived of their membranous investment, for they may be injurious to sufferers from heart disease either from their indigestibility or from irritant substances which they contain. Only those kinds of food which are quite easily digestible can be recommended.

Ice in any form whatever, whether as iced drinks, fruit ices, or ice pudding, may not only cause gastrodynia in cardiac sufferers but, as I have often enough observed, is capable of directly producing congestion of the liver. This must be kept in mind even when the medical attendant is compelled to prescribe ice for the relief of vomiting. At the same time nothing should be either eaten or drunk while it is very hot, as excitement of the heart's action is easily caused in that way.

It is impossible to urge too strongly that sufferers from heart disease always require a mixed diet. With them the use of a diet consisting exclusively of meat very easily leads to the excretion of urine containing an excessive amount of dissolved solids and supersaturated with uric acid. I have even seen cases in which over-indulgence in animal food appeared to have been the principal, if not the only, cause of irritation of the kidney with hypertrophy and dilatation of the heart. An entirely vegetable diet is no less injurious. In order to make up the requisite amount of nutritive material, such food must be taken in considerable quantities, whereby the stomach is over-filled, and apart from this the supposition that arterio-sclerosis may be prevented by a dietary consisting of carbohydrates has been proved to be erroneous. Indeed, the very reverse of this is the fact, for it has been found that calcification of the vessels is encouraged by such a diet. Thorough comminution and copious insalivation of what is eaten are as important in diseases of the heart as in diseases of the stomach.

There is great diversity of opinion on the subject of tobacco-smoking. Many think that smoking when not carried to excess is quite harmless in heart disease and others consider that even in the cases in which the patients have found their symptoms aggravated by the use of tobacco the normal conditions are sure to be restored by a few months' abstinence. My experience leads me to regard tobacco with great disfavour, for I have seen quite a number of instances in which an excessive use of it was the only cause that could be assigned for the production of chronic heart disease and arterio-sclerosis. In tobacco there are many substances besides nicotin that may act injuriously and for this reason the partial removal of the alkaloid, a process to which tobacco has often been subjected in recent years, is no guarantee that much smoking may have no ill consequences. I therefore always recommend patients suffering from heart disease either to give up smoking altogether or else to indulge in it most sparingly, and in the latter case to use very dry tobacco and a long mouthpiece or pipe. A patient should always be informed that smoking is bad for his heart disease. Some years ago I had an opportunity of observing how dangerous opium smoking is for the heart, the patient being a woman, 22 years of age. At first a great smoker of cigarettes and afterwards of opium, she gave up the practice for a considerable time when placed under strict supervision but the first attempt at renewal of opium smoking brought on a severe attack of cardiac failure for the relief of which it was necessary to use camphor and hot applications over the heart.

As a result of observations made by Oertel, it has been very much debated whether sufferers from heart disease ought to drink at meal times or not. I have, however, already stated that the only condition which requires attention here is that the stomach shall not be overfilled and the principal advantage of not drinking at meal times is that the patients when they do not drink eat less that when they drink. In the treatment of fatty heart and general adiposity, as well as in plethora, it is better not to drink but when it is desirable that the patients should have plenty of food there is absolutely no reason for the prohibition of drinking at meal times, provided that the measures of precaution already described are complied with.

The majority of sufferers from heart diseases feel themselves better if they take gentle exercise in the open air for a short time after meals. Sitting still is apt not only to bring on palpitation and shortness of breath, but also to. encourage the deposition of fat; it is therefore appropriate only when the latter condition is desirable or when the patients are too weak to take exercise after meals. In other cases exercise after meals is to be recommended. In heart disease it is evidently quite essential that the individual characteristics of the patients should be studied and that the treatment should be modified in correspondence with the symptoms.

The rules here given are for the most part applicable to. uncomplicated cases of chronic heart disease, whether valvular defects dne to a variety of causes, diseases of the myocardium, or cardiac neuroses. Heart disease associated with other morbid considerations, such as diseases of thestomach, intestines, liver, or kidneys, or with disorders of metabolism such as diabetes or gout, evidently requires special treatment. The same regimen is not suitable for a bedridden patient and for a robust individual who can walk for hours in the open-air, or for anæmic persons and for cases of plethora or corpulence. Strict regulation of the diet is requisite not only in the pre-compensation stagebut also after compensation is fully established, for it is commonly recognised how easily errors in diet may either. contribute to a renewal of cardiac troubles or may directly produce them. I have often seen this result follow the drinking of a glass of beer or champagne or the taking of a hearty meal. The practitioner should remember that the. more carefully he manages his cardiac cases during the intervals between their attacks the better will he succeed in averting relapses and in contributing to the relief of his. patients' sufferings and even to the prolongation of their. lives.

Bad Nauheim.

THE PHYSIOLOGICAL ACTION OF THE: NAUHEIM SPRINGS AND THE INDI-

CATIONS FOR THEIR USE,
CHIEFLY IN DISORDERS
OF THE CIRCULATION.

\section{BY PAUL C. FRANZE, M.D.}

ALTHOdGH Nauheim owes its present popularity in nosmall measure to an increased prevalence of heart affections, there can be little doubt that its widespread reputation is essentially attributable to the intrinsic merits of its waters. and to the balneological methods which have been evolved 